\title{
AFM Imaging of Natural Optical Structures
}

\author{
Dinara DALLAEVA ${ }^{1}$, Shikhgasan RAMAZANOV ${ }^{2}$, Elena PROKOPYEVA ${ }^{1}$, \\ Pavel KASPAR ${ }^{1}$, Pavel TOMANEK ${ }^{1}$ \\ ${ }^{1}$ Physics Department, Faculty of Electrical Engineering and Communication, \\ Brno University of Technology, Technicka 8, 61600 Brno, Czech Republic \\ ${ }^{2}$ SICLAB Limited liability company, 367030 Machachkala, st. M. Yaragskogo 75, \\ Dagestan Republic, Russia \\ xdalla02@stud.feec.vutbr.cz, ramazanv@mail.ru, xproko24@stud.feec.vutbr.cz, \\ xkaspa25@stud.feec.vutbr.cz, tomanek@feec.vutbr.cz
}

\begin{abstract}
The research in this field is focused to the investigation of biological structures with superior optical features. The study presents atomic force microscopy of biological optical structures on butterfly wings. The bright blue and dark black color scales exhibit the different topography. These scales were compared to the visually the same color scales of other two species of butterfies. The histograms of heights distribution are presented and show similar results for the scales of one color for different species.
\end{abstract}

\section{Keywords}

Atomic force microscopy, biological optical structure, butterfly scales, structural color.

\section{Introduction}

The coloration in living world is achieved by different ways: by pigmentation, by structure of the biological material and by their combination. A pigmentation is referred to the chemical colors and depends on the type and amount of colorants (pigments) in the material composition. The structure of the material influences its color because of light interaction with the surface and near-surface area (interference, diffraction, polarization) and pertains to physical colors. The structural coloration indicates the colors that could not be demonstrated only by pigments [1].

A brilliance perception of material color depends on roughness and structure: shining surface looks more colorful in comparison to lusterless surface of the same color but different morphology.

The structure containing quasi-periodical architecture of chitin can show the structural colors 22 be- cause of refractive index contrast between chitin and air. Photonic architecture of blue butterflies was reported in [3], 4], 5], [6]. Photonic structure of butterfly wings contains chitin and air and controls the light propagation, absorption, and reflection. Different colors can be created by the chemically identical material. Refractive index of chitin is $n=1.52$ 3. So the layered morphology of the wings consisted of two media with refractive index contrast allows to define the wing surface as a structural color material.

Exceptional optical characteristics make these structures useful for a number of applications, such as design of quasi-ordered structures [7] to increase the efficiency of solar cells [3], fabrication of optical fibers, waveguides 2], different kinds of sensors (chemical, gas, temperature) [2, 4], 5], 8, photodetectors 9], replications for photonic crystals 9], efficient lasers [10]. The structural control can be used to impact the optical properties of nontoxic colorants, coatings, microand nano-structured textiles [7, photonic papers [3 and other surfaces from antiglare to iridescence ones.

These structures attract the attention of scientists, and there are a number of studies of scales structure by scanning and transmission electron microscopy [5], [6], 7].

\section{Materials and Methods}

In this study we deal with Morpho didius, also known as Giant Blue Morpho, it dwells in Neotropic ecozone. The sample preparation included just cutting off a certain piece of the wings by scissors.

We reported at [11] the temperature behavior of the Vanessa atalanta wings by heating of the sample during AFM measurements. The wettability of the wings is also of a great interest (Fig. 1). Droplets of water 


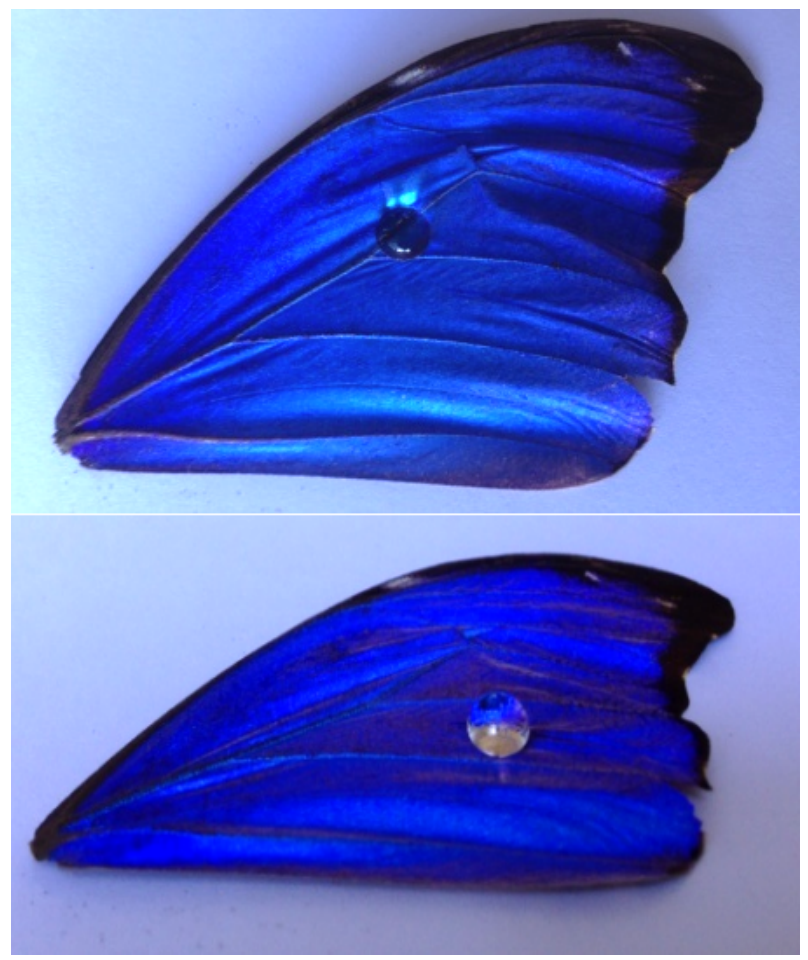

Fig. 1: A droplet of water on the wing surface.

fall down from the wings without percolation inside or through the wing structure. It helps butterfly to survive in nature, and it can find commercial application.

On the other side, it is possible to observe the tunable structural coloration. Figure 2 demonstrates changing of the color after alcohol applying observed by the naked eye. These phenomena of natural photonic crystals were also described in 3]. Oversimplified example of sensing mechanism is observed here. The refractive index of methanol is $n=1.33$ [12].

Accordingly to [8] the decreasing of refractive index differences causes the color appearance of a higher wavelength. The structure represented by 1-D, 2-D, and 3-D photonic structures [3] of the wings is undisguised and attracts attention as a sensor [4].

The other two species with strongly marked iridescent blue and dark black colors were taken for comparison the result of morphology studies. These are Polyommatus amandus and Vanessa atalanta belong to the Lycaenidae and Nymphalidae families correspondingly.

Atomic force microscopy (AFM) provides the possibility to observe local properties, micro- and nanotopography and structure of the surface. AFM is an analytical method with high quality, sensibility, reliability, precision, and resolution. The data of AFM show 3D image of the surface and process statistical data of the surface roughness such as histograms of heights distribution. Morphology of wings was studied by atomic force microscope (AFM) Ntegra Prima

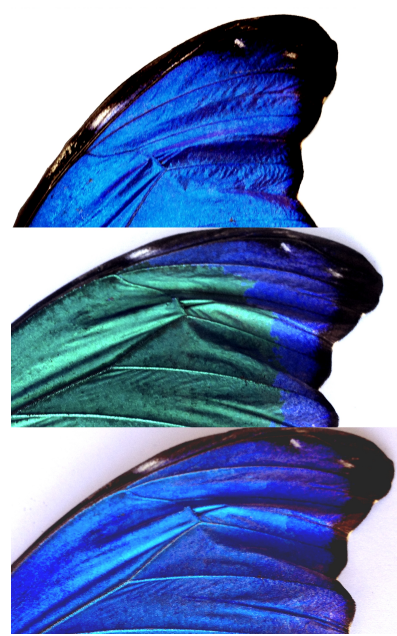

Fig. 2: Color changing of the wing under the influence of methanol: upper image is the piece of wing before applying of alcohol, in the middle - after applying of alcohol, bottom - two minutes after applying alcohol.

(NTMDT production). The humidity during the measurements was $40 \pm 1 \%$ and temperature $24 \pm 1{ }^{\circ} \mathrm{C}$. $\mathrm{HA}-\mathrm{NC}$ cantilevers were used with a tip curvature radius less than $10 \mathrm{~nm}$ [13. The data were processed by software Nova, provided with microscope package. AFM method was chosen to study the scales morphology since the cover scales play a significant role in color shaping.

\section{Experimental Results}

Size of the scales features various from nanometers to micrometers. Optical system of the microscope was used to choose the scales for scanning (Fig. 3).

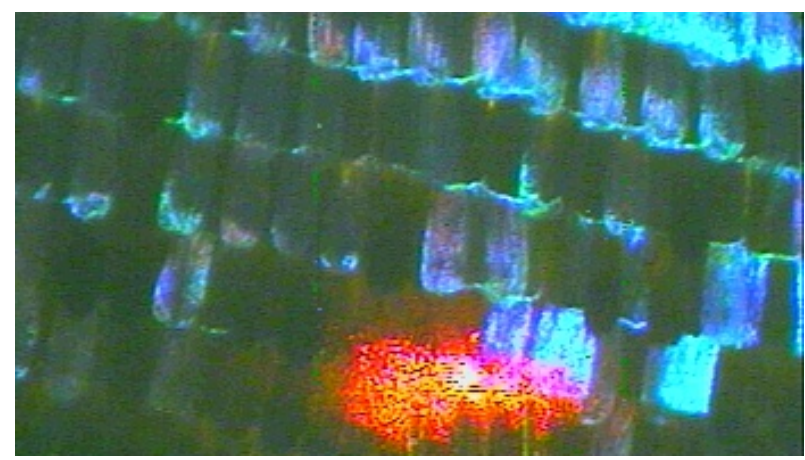

Fig. 3: The wing during the AFM investigation. The sample is illuminated in order to distinguish different color scales. Red spot represents a laser reflection from the AFM cantilever and is used for the registration of the cantilever bending.

Scales are overlapped, and separate colors have different micro- and nanostructures (Fig. 4, Fig. 5 , Fig. 60. These structures are not completely ideal in periodi- 
city, but nevertheless they can exhibit photonic band gap [8].

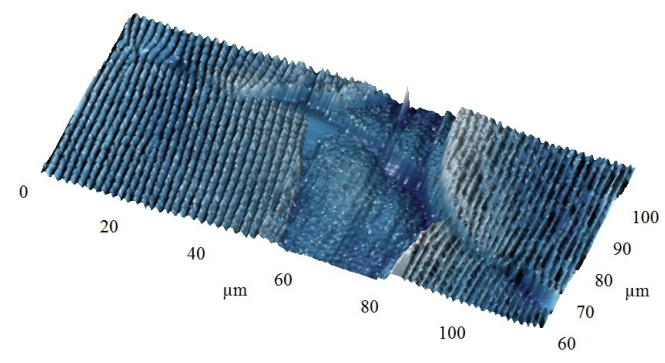

Fig. 4: AFM image of Morpho didius of the same blue color scales.

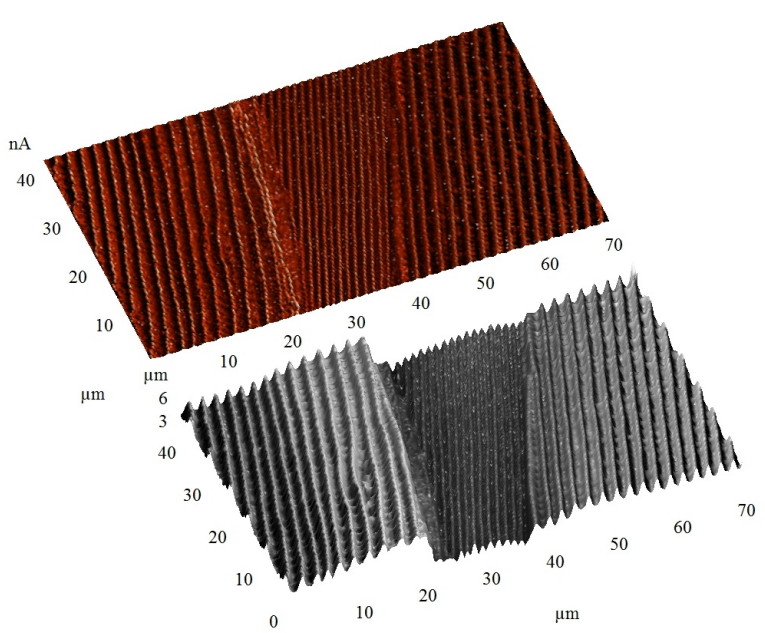

Fig. 5: AFM image of Morpho didius in two scales: black and blue. Upper image is obtained by AFM method of semicontact error to confirm the precision of morphology measurement and bottom is the scan of AFM in a semicontact mode.

The lower size scanning $(5 \times 5 \mu \mathrm{m})$ was made in order to find the distinctions between the different color scales (Fig. 6).

In this figure, a structural color is observed. Parallel ridges are observed for both colors, but the bridges between them look differently. Besides there is a complex structure of columns under them for blue color scales. The similar effect exists for other species - e. g. Polyommatus amandus butterfly (Fig. 7). The structural color occurs because of light interaction with surface features. Quasi-ordered slits and grooves are well distinguished, and iridescence depends on the angle of observation.

Figure 7 shows that the optical structures are not limited only by ribs on the surface, but we can observe

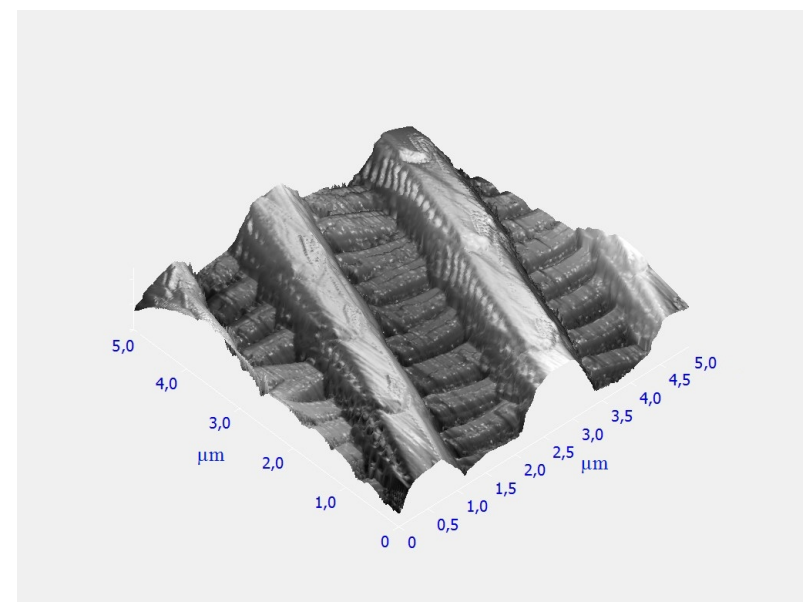

(a) AFM image of black scale.

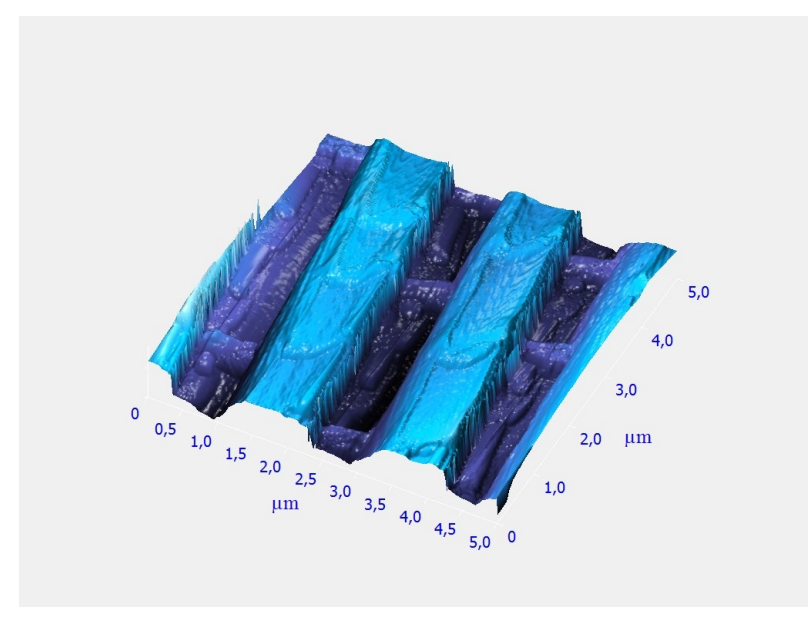

(b) AFM image of the blue scale.

Fig. 6: AFM semi-contact image of Morpho didius butterfly scales.

them even between ribs and so consider a wing as a layered structure.

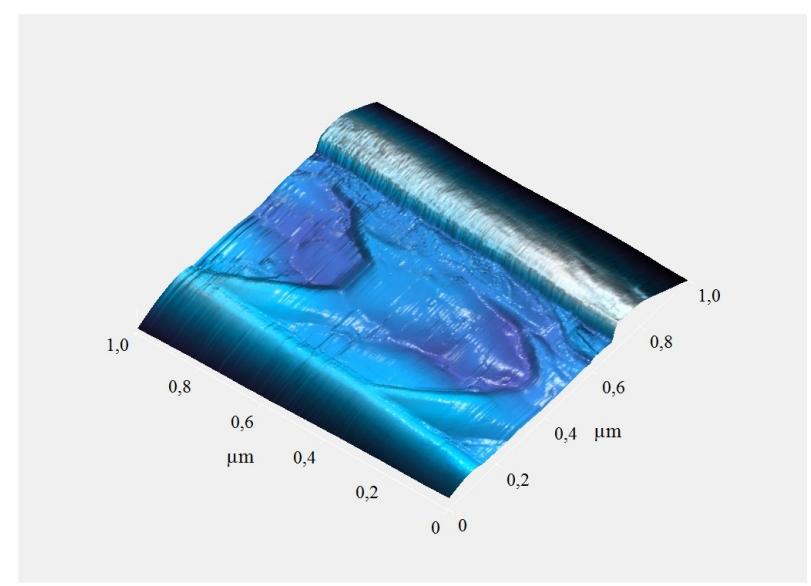

Fig. 7: AFM semi-contact image of a blue scale wing of Polyommatus amandus butterfly. 
Data of AFM measurements were processed by program Nova, it allows to plot a histogram with the empirical distribution of heights and holes. The topography and high distribution histograms of the black color scales for two different butterflies are shown in Fig. 8 , Fig. 9 and blue color scales - in Fig. 10, Fig. 11 .

Figure 8, Fig. 9, Fig. 10, Fig. 11 demonstrate a fragile structure of wing scales with different colors. Histograms for scale surface with black color have the area of height amount decreasing (Fig. 8(b), Fig. 9(b) but the histograms for blue color scales shows the continuous growth of heights (Fig. 10(b), Fig. 11(b) . It could be explained by optical properties of the surface that can be observed by naked eye: the dull surface abounds in valleys and has almost no hills, so this surface does not glare and reflect. These and similar black color structures could also be interesting for stealth technology. The diffusing surface has the extended area and is proved by the presence of two peaks in histograms.

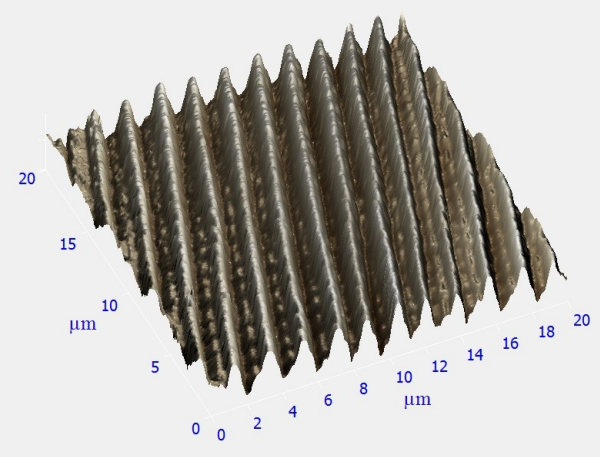

(a) AFM semi-contact image of the wing black scale.

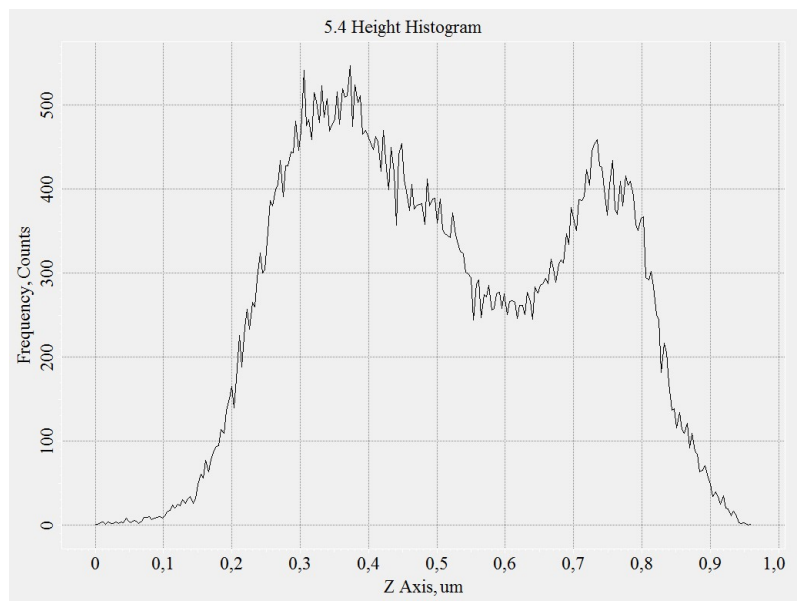

(b) Histogram of heights distribution of the wing black scale.

Fig. 8: AFM study of Morpho didius butterfly black scales.

\section{Conclusion}

We report the AFM results of the butterfly wing scale morphology. The wing structure defines the color in the visible range. These periodical structures which are important for butterfly survival functions also represent both theoretical meaning for different fields (ecology, biology, physics) and the importance to the development of inexpensive, reproducible devices with various optical features. Examples of biological structures with photonic structures are described with an explanation of two different colors formation: iridescent and antiglare. Impressive optical properties are combined with fine wettability and sensing abilities.

\section{Acknowledgment}

Research described in the paper was financially supported by the European Centre of Excellence CEITEC CZ.1.05/1.1.00/02.0068, by project Sen-

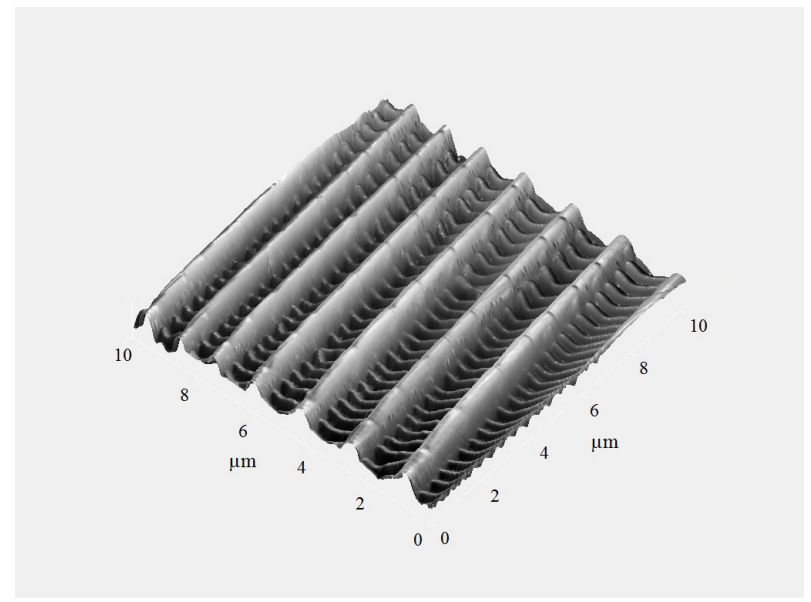

(a) AFM semi-contact image of the wing black scale.

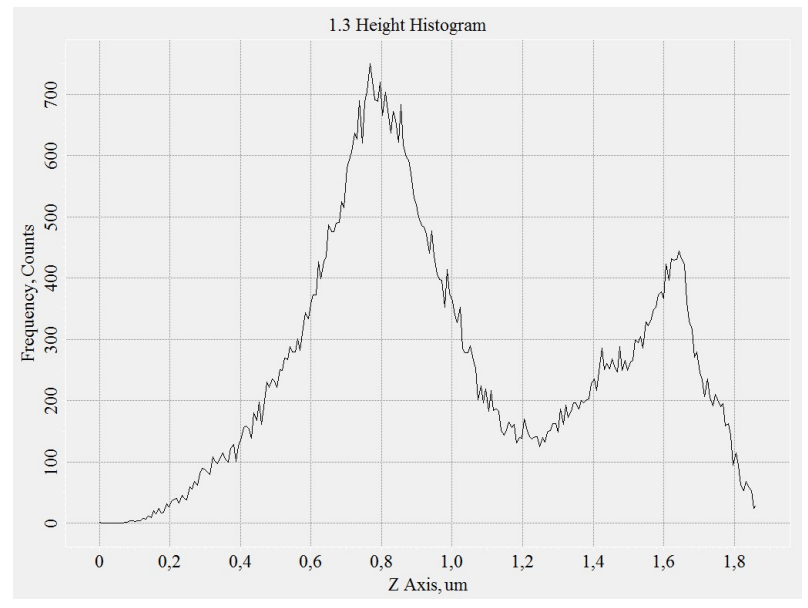

(b) Histogram of heights distribution of the wing black scale.

Fig. 9: AFM study of Vanessa atalanta butterfly black scales. 


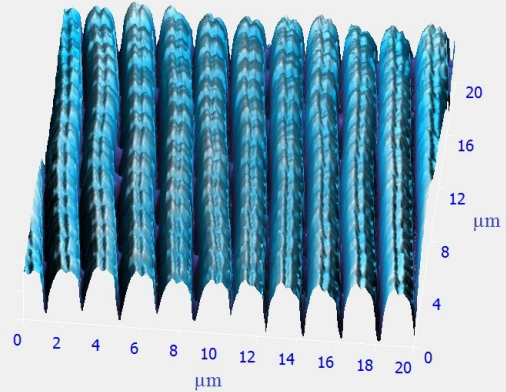

(a) AFM semi-contact image of the wing black scale.

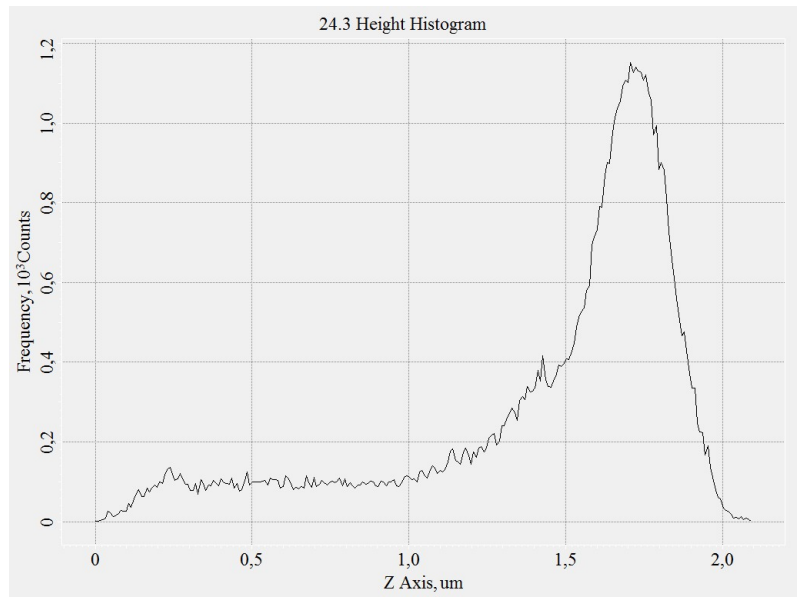

(b) Histogram of heights distribution of the wing black scale.

Fig. 10: AFM study of Morpho didius butterfly blue scales.

sor, Information and Communication Systems SIX CZ.1.05/2.1.00/03.0072 as well as by grant FEKT-S14-2240.

\section{References}

[1] MCPHEDRAN, R. C., N. A. NICOROVICI, D. R. MCKENZIE, G. W. ROUSE, L. C. BOTTEN, V. WELCH, A. R. PARKER, M. WOHLGENNANT and V. VARDENY. Structural Colours through Photonic Crystals. Physica B: Condensed Matter. 2003, vol. 338, iss. 1-4, pp. 182-185. ISSN 09214526. DOI: 10.1016/S0921-4526(03)00483-6.

[2] KERTESZ, K., G. PISZTER, E. JAKAB, Z. BALINT, Z. VERTESY and L. P. BIRO. Color Change of Blue Butterfly Wing Scales in an Air - Vapor Ambient. Applied Surface Science. 2013, vol. 281, iss. 1, pp. 49-53. ISSN 0169-4332. DOI: $10.1016 /$ j.apsusc.2013.01.037.

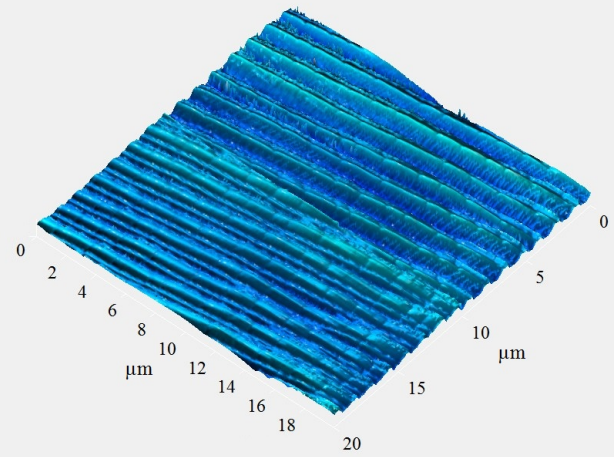

(a) AFM semi-contact image of the wing black scale.

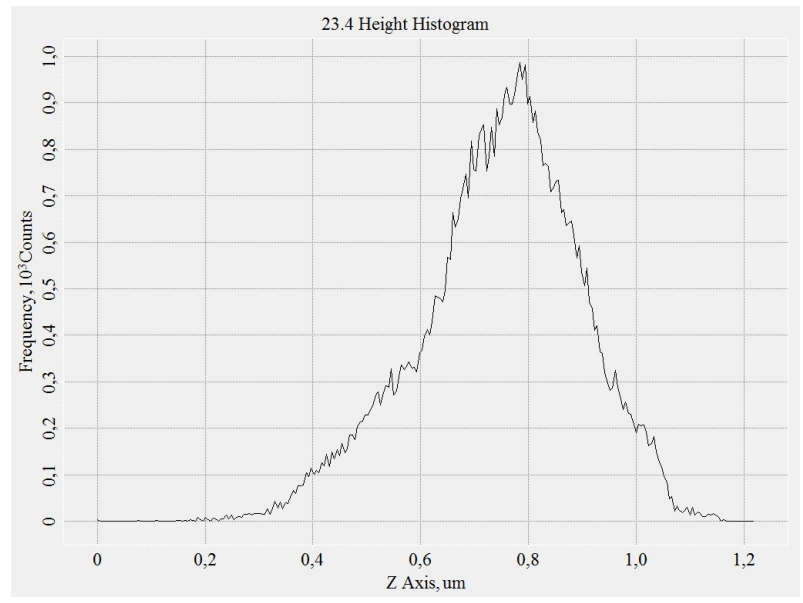

(b) Histogram of heights distribution of the wing black scale.

Fig. 11: AFM study of Polyommatus amandus butterfly blue scales.

[3] XU. J. and Z. GUO. Biomimetic Photonic Materials with Tunable Structural Colors. Journal of Colloid and Interface Science. 2013, vol. 406, iss. 1, pp. 1-17. ISSN 0021-9797. DOI: $10.1016 /$ j.jcis.2013.05.028.

[4] KERTESZ, K., G. PISZTER, E. JAKAB, Z. BALINT, Z. VERTESY and L. P. BIRO. Temperature and Saturation dependence in the Vapor Sensing of Butterfly Wing Scales. Materials Science and Engineering C. 2014, vol. 39, iss. 1, pp. 221-226. ISSN 0928-4931. DOI: $10.1016 /$ j.msec.2014.03.014.

[5] JIANG, T., Z. PENG, W. WU, T. SHI and G. LIAO. Gas Sensing using Hierarchical Micro/Nanostructures of Morpho Butterfly Scales. Sensors and Actuators A. 2014, vol. 213, iss. 1, pp. 63-69. ISSN 0925-4005. DOI: $10.1016 /$ j.sna.2014.04.002. 
[6] VIDAL, B. C. Butterfly Scale Form Birefringence Related to Photonics. Micron. 2011, vol. 42, iss. 8, pp. 801-807. ISSN 0968-4328. DOI: $10.1016 /$ j.micron.2011.04.006.

[7] KERTESZ, K., G. MOLNAR, Z. VERTESY, A. A. KOOS, Z. E. HORVATH, G. I. MARK, L. TAPASZTO, Zs. BALINT, I. TAMASKA, O. DEPARIS, J.-P. VIGNERON and L. P. BIRO. Photonic Band Gap Materials in Butterfly Scales: A Possible Source of "Blueprints". Materials Science and Engineering B. 2008, vol. 149, iss. 3, pp. 259-265. ISSN 0921-5107. DOI: $10.1016 /$ j.mseb.2007.10.013.

[8] TAMASKA, I., K. KERTESZ, Z. VERTESY, Z. BALINT, A. KUN, S. H. YEN and L. P. BIRO. Color Changes upon Cooling of Lepidoptera Scales Containing Photonic Nanoarchitectures, and a Method for Identifying the Changes. Journal of Insect Science. 2013, vol. 13, no. 87, pp. 1-15. ISSN 1536-2442. DOI: 10.1673/031.013.8701.

[9] HAN, Z., S. NIU, L. ZHANG, Z. LIU and L. REN. Light Trapping Effect in Wing Scales of Butterfly Papilio Peranthus and its Simulations. Journal of Bionic Engineering. 2013, vol. 10, iss. 2, pp. 162-169. ISSN 1672-6529. DOI: 10.1016/S1672-6529(13)60211-5.

[10] BIRO, L. P., K. Kertesz, Z. VERTESY, G. I. MARK, Z. BALINT, V. LOUSSE, and J-P. VIGNERON. Living Photonic Crystals: Butterfly Scales - Nanostructure and Optical Properties. Materials Science and Engineering C. 2007, vol. 27, iss. 5-8, pp. 941-946. ISSN 0928-4931. DOI: $10.1016 /$ j.msec.2006.09.043.

[11] DALlAEVA, D. and P. TOMANEK. AFM Study of Structure Influence on Butterfly Wings Coloration. Advances in Electrical and Electronic Engineering. 2012, vol. 10, iss. 2, pp. 120-124. ISSN 1804-3119. DOI: 10.15598/aeee.v10i2.616.
[12] Refractive index database [online]. 2014. Available at: http://refractiveindex.info/legacy/ ?group=LIQUIDS\&material=Methanol

[13] Specification of $\mathrm{HA} \mathrm{NC}$ probe series. NTMDT [online]. 2014. Available at: http://www. ntmdt-tips.com/products/view/ha-nc.

\section{About Authors}

Dinara DALLAEVA was born in 1988 in Kaspiysk, Russian Federation. She received her M.Sc. degree from Dagestan State University in 2010. Presently, she is a Ph.D. student in Physical Electronics and Nanotechnology at Faculty of Electrical Engineering and Communication, Brno University of Technology. Her research interests include scanning probe microscopy, wide band gap semiconductors.

Shikhgasan RAMAZANOV is a Ph.D. in Physics and Mathematics. His research interest concerns graphene preparation.

Elena PROKOPYEVA is a Ph.D. student in Physical Electronics and Nanotechnology at Faculty of Electrical Engineering and Communication, Brno University of Technology. Her study covers optical and electrical properties of biological materials.

Pavel KASPAR is a Ph.D. student in Physical Electronics and Nanotechnology at Faculty of Electrical Engineering and Communication, Brno University of Technology. His research is dedicated to image processing and Raman spectroscopy.

Pavel TOMANEK is a Professor in Applied Physics at Faculty of Electrical Engineering and Communication, Brno University of Technology. His research interests cover various aspects of optical nanometrology, holography, optical fiber sensors, bio-optics. Fellow EOS (2008), member of EOS, SPIE, OSA, IEEE, MRS, CSSF, JCMF, CSNMT. 